\title{
Assessment of electrical activity in the supra and infra hyoid muscle in individuals with type 2 diabetes mellitus
}

\author{
Tiago Lima Santos, Patricia Maria Mendes Balata, Lucas Albuquerque, Marina Cerqueira Rosdaibida Gomes, \\ Deniele Bezerra Lós, Lucio Vilar, Sílvia Regina Arruda de Moraes
}

From 20th Brazilian Diabetes Society Congress

Porto Alegre, Brazil. 11-18 November 2015

\section{Background}

It is believed that muscle changes caused by Diabetes mellitus can impact supra and infra-hyoid muscles, reflecting the phonation process. However, there are no studies evaluating the behavior of the extrinsic muscles of the larynx in phonation activities in this population.

\section{Objective}

To evaluate the electrical activity of supra and infrahyoid muscles in individuals with type 2 diabetes mellitus.

\section{Materials and methods}

Sample was composed of thirty female adults, aged between 40 and 60 years, distributed in Diabetes group and Control group and they were submitted to a electromyography exam with electromyography MIOTEC ${ }^{\circledR}$ (Rio Grande do Sul, Brazil) connected to a notebook SAMSUMG brand provided the Miotool $200^{\circledR}$ software, using windowing 32 and gain equal to 2000 for each channel. An electrode reference and three channels connected to active sensors with connection $\operatorname{SDS} 5000^{\circledR}$ by claws were used. The signal analysis was performed with the Miograph $2.0^{\mathbb{B}}$ software. For normalization of the supra-hyoid group (HS) swallowing incomplete maneuver and the infra-hyoid ( $\mathrm{IH})$, the tongue retracted technique was used. Then, it was performed the catchment of the muscular electrical activity through the rest moment following by the evaluation during vowel/ $/$ / vocalization and the usual speech. It had been used the $t$ test to calculate the differences between the averages of electrical activity of the groups evaluated.

\section{Results}

There was a reduction in the electrical activity of supra and right and left infra-hyoid muscles during vocalization of the vowel/ $/ \varepsilon /$, normalized by rest moment and reduced electrical activity during normal speech (count 1 to 10) normalized by rest moment only the suprahyoid muscle in the diabetic group $(\mathrm{p}<0.05)$.

\section{Conclusion}

Results suggest that diabetes promotes reduction of muscle electrical activity in phonation activities that are detected when they are normalized by rest moment.

Published: 11 November 2015

doi:10.1186/1758-5996-7-S1-A14

Cite this article as: Santos et al:: Assessment of electrical activity in the supra and infra hyoid muscle in individuals with type 2 diabetes mellitus. Diabetology \& Metabolic Syndrome 2015 7(Suppl 1):A14.

\footnotetext{
* Correspondence: sramoraes@gmail.com

Universidade Federal de Pernambuco, Recife, Brazil
} 